\title{
A contest model of a professional sports league with two-sided markets
}

\author{
Dietl, Helmut ; Duschl, Tobias ; Franck, Egon ; Lang, Markus
}

\begin{abstract}
This paper develops a model of a professional sports league with network externalities by integrating the theory of two-sided markets into a two-stage contest model. In professional team sports, the competition of the clubs functions as a platform that enables sponsors to interact with fans. In these club-mediated interactions, positive network effects operate from the fan market to the sponsor market, while positive or negative network effects operate from the sponsor market to the fan market. We show that the size of these network effects determines the level of competitive balance within the league. If the market potential of the sponsors is small (large), competitive balance increases (decreases) with stronger combined network effects. We further deduce that clubs benefit from stronger combined network effects through higher profits and that network externalities can mitigate the negative effect of revenue sharing on competitive balance. Finally, we derive implications for improving competitive balance by taking advantage of network externalities. For example, our model suggests that an increase in the market potential of sponsors produces a more balanced league.
\end{abstract}

DOI: https://doi.org/10.1515/jbnst-2012-0311

Posted at the Zurich Open Repository and Archive, University of Zurich

ZORA URL: https://doi.org/10.5167/uzh-63257

Journal Article

Published Version

Originally published at:

Dietl, Helmut; Duschl, Tobias; Franck, Egon; Lang, Markus (2012). A contest model of a professional sports league with two-sided markets. Jahrbücher für Nationalökonomie und Statistik, 232(3):336-359.

DOI: https://doi.org/10.1515/jbnst-2012-0311 


\title{
A Contest Model of a Professional Sports League with Two-Sided Markets
}

\author{
By Helmut Dietl, Tobias Duschl, Egon Franck, and Markus Lang, Zurich* \\ JEL L11; L13; L83; M21 \\ Competitive balance; contest; multisided market; network externalities; team sports league.
}

\begin{abstract}
Summary
This paper develops a model of a professional sports league with network externalities by integrating the theory of two-sided markets into a two-stage contest model. In professional team sports, the competition of the clubs functions as a platform that enables sponsors to interact with fans. In these club-mediated interactions, positive network effects operate from the fan market to the sponsor market, while positive or negative network effects operate from the sponsor market to the fan market. We show that the size of these network effects determines the level of competitive balance within the league. If the market potential of the sponsors is small (large), competitive balance increases (decreases) with stronger combined network effects. We further deduce that clubs benefit from stronger combined network effects through higher profits and that network externalities can mitigate the negative effect of revenue sharing on competitive balance. Finally, we derive implications for improving competitive balance by taking advantage of network externalities. For example, our model suggests that an increase in the market potential of sponsors produces a more balanced league.
\end{abstract}

\section{Introduction}

The professional team sports industry has a unique organizational structure. It is the only industry in which production is organized by leagues. This unique organizational structure is the result of the industry-specific production and competition process. Industry outsiders often tend to regard individual teams as firms and treat them as production units. Unlike an automobile firm, however, an individual team cannot produce a marketable product. Each team needs at least one opponent to play a match. However, even a match between two teams is not an attractive product. The individual matches must be upgraded by integrating them into an organized championship race. This upgrade, which gives each individual match additional value within the larger context of the championship race, is managed by the league.

* Previous versions of this article were presented at the 86th Annual Conference of the Western Economic Association in San Diego, the 2nd European Conference in Sport Economics in Cologne, Germany and the 10th Annual Meeting of the European Academy of Management (EURAM) in Rome, Italy. We would like to thank two anonymous referees and conference participants especially Harald Dolles, Bernd Frick, Paul Madden, Thomas Peeters, Leigh Robinson and Stefan Szymanski - for helpful comments and suggestions. Financial assistance was provided by a grant of the Swiss National Science Foundation (Grant No. 100014-120503) and the research fund of the University of Zurich (Grant No. 53024501). 
From a sports perspective, each team within a league wants to win as many games as possible. Economically, however, teams are not so much competitors but are rather complementors. The quality or economic value of the championship race depends to a large extent on the level of competitive balance. Unlike Toyota and Ford, which prefer weak competitors in their industry, sports teams like Real Madrid, the New York Yankees, and the Dallas Cowboys benefit from having strong opponents within their leagues. A more balanced league usually produces a more attractive - that is, economically more valuable - product. $^{1}$

The clubs' competition provides the platform for the interaction of various market sides such as fans, advertisers and sponsors, the media, and merchandising companies. These interactions via an intermediary platform creates what is called a "multisided market." Each of the distinct market sides demands a specific good or service provided by the intermediary. Frequently, the market sides do not interact with each other directly; however, they exert network externalities on each other. These externalities influence the market's demand structure and the intermediary's pricing schemes.

Fans demand competition and the experience of a sports event, advertisers and sponsors demand an audience that they can inform about their products or services, the media demand an audience willing to pay for the use of their services, merchandising companies demand customers who want to buy their articles, etc. An interaction between two market sides only takes place because of the underlying sports event. Fans would hardly consume advertisement content if there were not a match taking place that featured their favorite team. Merchandising companies would sell many fewer fan articles if their products were not linked to an active sports team, and so on. These examples underline the importance of the clubs' competition to act as a platform for the different market sides that interact and exert network externalities on each other.

We add to the literature by contributing to two different strands of literature: on the one hand, the literature on multisided markets and on the other hand, the literature on analytical models of sports leagues. To the best of our knowledge, we are the first to integrate the theory of two-sided markets into a contest model of a professional team sports league. ${ }^{2}$ Our model can then be used as a basic framework to analyze the effect of different cross-subsidization schemes in team sports leagues.

In particular, this paper develops a model of a professional sports league with network externalities by integrating the theory of two-sided markets into a two-stage contest model. In professional team sports, the competition of the clubs functions as a platform that enables sponsors to interact with fans. In these club-mediated interactions, positive network effects operate from the fan market to the sponsor market, while positive or

1 According to the so-called "uncertainty of outcome" hypothesis (Rottenberg 1956), fans prefer to attend games with an uncertain outcome and enjoy close championship races. For empirical contributions that analyze the relation between competitive balance and match attendance, see Downward and Dawson (2000), Borland and MacDonald (2003) and Szymanski (2003).

2 Notable exemptions include Bae and Kwon (2008) and Budzinski and Satzer (2010). Bae and Kwon (2008) present an analytical model in which teams in a sports leagues compete for players and fans. In their framework, two-sided network effects are important because a club with a larger portion of talented players attracts more fans and, simultaneously, players want to play for a large-market club. However, they do not explicitly model the competition of the clubs via contest theory. Budzinski and Satzer (2010) develop a conceptual framework by describing the platform elements of professional suppliers of sports events. 
negative network effects operate from the sponsor market to the fan market. ${ }^{3}$ In line with standard results in the literature on two-sided markets (Armstrong 2006; Kaiser/Wright 2006; Rochet/Tirole 2006), we derive that clubs react to stronger fan-related network externalities by charging lower prices to fans and higher prices to sponsors. The opposite holds true for weaker negative or stronger positive sponsor-related network externalities. New and potentially important for professional sports, our analysis further shows that the size of these network externalities determines the level of competitive balance within the league. Depending on the market potential of the sponsors, competitive balance increases (small market potential) or decreases (large market potential) with stronger combined network effects. Moreover, we show that clubs benefit from the presence of network externalities because club profits increase with stronger combined network effects. The paper can be of interest to policy-makers in a professional team sports league because we derive recommendations of how to improve competitive balance by taking advantage of network externalities. Our model suggests that an increase in the market potential of sponsors produces a more balanced league because the small club will increase its talent investments more than the large club in equilibrium. Finally, we show that network externalities can mitigate the negative effect of revenue sharing on competitive balance.

Taking a closer look at major team sports leagues worldwide, one can find a number of phenomena that may be explained by our model. For example, the differences in match attendance and average ticket prices between national leagues in European football are accompanied by strong divergences in sponsor-related revenues. While match-day income (e.g., ticket sales and others) in the 2008/2009 season with €665m was higher in the English Premier League than in the German Bundesliga, where it amounted to $€ 363 \mathrm{~m}$, a look at commercial revenue (e.g., sponsorship and others) yields the opposite picture, there, the Premier League generated $€ 527 \mathrm{~m}$ and the Bundesliga $€ 723 \mathrm{~m}$ (see Deloitte \& Touche 2010). This observation provides anecdotal evidence for our theoretical model and mirrors the trade-off between fan-related and sponsor-related revenues. The quota for sponsorship in many North American major leagues represents another example; even though teams might be able to obtain higher revenues by increasing the amount of sponsoring/advertisements, the majority of teams refrains from posting advertisements on jerseys. ${ }^{4}$

The paper is structured as follows. Section 2 reviews the related literature. In Section 3, we present our model with its notation and main assumptions. We specify fan and sponsor demand, the quality of the competition and club profits. In Section 4, we solve the two-stage game, derive the subgame-perfect equilibria and discuss the results. Section 5 highlights policy implications regarding competitive balance and revenue sharing. Finally, Section 6 points out possible extensions and concludes the paper.

\section{Literature review}

Economists have designed various models of sports leagues. In an early contribution, El-Hodiri and Quirk (1971) developed a dynamic decision-making model of a profes-

\footnotetext{
3 See Becker and Murphy (1993) for a discussion on advertisements as a good or bad. For further analysis of advertisements see, e.g., Depken and Wilson (2004) and Reisinger et al. (2009).

4 Note that teams in the National Football League (NFL) are allowed to post a sponsor on their jerseys. Only a small proportion of teams, however, makes use of this opportunity.
} 
sional sports league and incorporated certain fundamental features of the North American sports industry such as the reserve clause, player drafts and the sale of player contracts among teams. They show that revenue sharing does not influence competitive balance and thus confirm the "invariance proposition". ${ }^{5}$ Fort and Quirk (1995) derive similar results in an updated, static version of the El-Hodiri and Quirk model. Atkinson rt al. (1988) contradict the invariance proposition and show that revenue sharing can improve competitive balance. In their model, Atkinson et al. adopt a pool-sharing arrangement and a club revenue function that depends on the team's performance and on the performance of all other teams. Their result is supported by Marburger (1997), who builds his model on the assumption that fans care about the relative and absolute quality of teams. Vrooman (1995) shows that sharing the winning-elastic revenue does not affect competitive balance, while sharing the winning-inelastic revenue does improve competitive balance. Késenne (2000a) develops a two-team model consisting of a large- and a small-market club and shows that a payroll cap, defined as a fixed percentage of league revenue divided by the number of teams, will improve competitive balance as well as the distribution of player salary within the league (Késenne 2007).

The recent sports economics literature has suggested modeling a team sports league by making use of contest theory. ${ }^{6}$ In his seminal article, Szymanski (2003) applied Tullock's (1980) rent-seeking contest to ascertain the optimal design of sports leagues. Based on a model of two profit-maximizing clubs and a club revenue function that depends on the relative quality of the home team, Szymanski and Késenne (2004) show that gate revenue sharing decreases competitive balance. This result is driven by the so-called "dulling effect." The dulling effect describes the well-known fact in sports economics that revenue sharing reduces the incentive to invest in playing talent. Dietl and Lang (2008) confirm this finding and further show that gate revenue sharing increases social welfare.

As this brief review of the sports economics literature shows, analytical models in sports are mainly focused on the effect of cross-subsidization schemes such as reserve clauses, revenue sharing and salary caps on competitive balance without taking into account that the competition of the clubs provides the platform for the interaction of various market sides (fans, sponsors, advertisers and the media). These club-mediated interactions of different market sides create a "multisided market."

Research related to multisided markets is flourishing and has been conducted on a broad range of topics and industries: e.g., software platforms (Evans et al. 2004), payment systems (Rochet/Tirole 2002; Schmalensee 2002; Wright 2003, 2004), the Internet (Baye/Morgan 2001; Caillaud/Jullien 2003) and media markets (Kaiser/Wright 2006; Crampes et al. 2009; Reisinger et al. 2009). More general models have been proposed by Rochet and Tirole (2003b), Armstrong (2006), Armstrong and Wright (2007) and Belleflamme and Toulemonde (2009). The analysis of two-sided markets draws on the literature on network externalities and multi-product pricing (Rochet/Tirole 2006). Pricing decisions account for originally non-internalized externalities among the market sides. For example, the market side that exerts larger positive externalities on the other market side is subsidized via a lower price (see Armstrong 2006; Kaiser/

5 The "invariance proposition" goes back to Rottenberg (1956) and states that the distribution of playing talent between clubs in professional sports leagues does not depend on the allocation of property rights to players' services. See also Vrooman (1996).

6 The first approaches in contest theory were made by Lazear and Rosen (1981), Green and Stokey (1983) and Nalebuff and Stiglitz (1983). 
Wright 2006). Apart from implications for agent behavior in two-sided markets and optimum pricing decisions, research also has established important implications for economic policy. It has been shown that measures which are conducive in traditional markets may be ineffective or negative in two-sided markets (Wright 2004; Evans/Schmalensee 2005). For example, two-sided markets may show price structures that do not reflect a meaningful economic relationship between prices and costs on either side of the market considered by itself, which matters for antitrust analysis (Evans 2003; Rochet/Tirole 2003). Despite the large variety of applications, the theory of multisided markets has not yet been applied to contest models of professional sports leagues. Our paper tries to fill the gaps in the literature on sports economics and multisided markets by developing a simple contest model of a professional team sports league with two market sides and network externalities.

\section{Model setup}

We model a professional team sports league with two clubs, denoted as 1 and 2 . The clubs are asymmetric with respect to their market size - that is, there is one large-market club and one small-market club. Each club $i \in\{1,2\}$ invests independently a certain amount $x_{i} \geq 0$ in playing talent to maximize its profits. ${ }^{7}$ Talent is measured in perfectly divisible units that can be hired at a competitive labor market.

In our model, the competition of the clubs provides the platform that serves as the intermediary between two groups: fans and sponsors. Fans can consume sports competition by watching a match, while sponsors are attracted to the competition because sports events draw large crowds of potential customers and help to build a positive corporate image. The size of the crowd can then be leveraged through media coverage - an effect that we model indirectly. The attractiveness of a sports event for sponsors increases with the number of fans watching. The presence of sponsors, in turn, may have a negative effect on the attractiveness of the event for the fans. These indirect effects are modeled as network externalities in the sponsor and fan demand functions.

The timing of the model features a two-stage structure:

1. Stage: Clubs invest independently in playing talent with the objective of maximizing their own profits. Talent investments determine the win percentages and thus the quality of the competition of the two clubs.

2. Stage: Given a certain quality of competition, clubs charge prices for fans and sponsors taking into account the network externalities that operate from one market side to the other. Next, fans and sponsors make their decisions and each club then generates its own revenues dependent on the decisions of fans and sponsors.

In the sections that follow, we derive the demand functions of fans and sponsors under network externalities and specify the quality of the competition. Finally, we derive club revenues, costs and profits.

\subsection{Demand of fans and sponsors under network externalities}

Following the literature on two-sided markets (e.g., Armstrong 2006), the linear demand functions are defined as follows. We assume that the fans of club $i$ demand the quantity $q_{i}^{f} \geq 0$ given by

7 If not otherwise stated, henceforth $i, j \in\{1,2\}$, with $i \neq j$. 


$$
q_{i}^{f}=m_{i}^{f}-\frac{p_{i}^{f}}{\theta_{i}}+n^{s} q_{i}^{s},
$$

while the amount of advertising $q_{i}^{s} \geq 0$ that sponsors place at club $i$ is given by ${ }^{8}$

$$
q_{i}^{s}=m^{s}-\frac{p_{i}^{s}}{\theta_{i}}+n^{f} q_{i}^{f}
$$

with prices $p_{i}^{f} \geq 0, p_{i}^{s} \geq 0$, quality of the competition $\theta_{i}>0$, market sizes $m_{i}^{f}>0$, $m^{s}>0$, and network effects $n^{f} \in[0,1), n^{s} \in(-1,1)$.

The price fans have to pay to be able to watch a match, is denoted by $p_{i}^{f}$, while $p_{i}^{s}$ stands for the price sponsors have to pay for advertisements. Clubs can charge fans for watching the match by selling tickets and also, indirectly, by collectively or individually selling media rights. Through ticket sales, clubs directly generate revenues from fan attendance. Through media rights sales, clubs indirectly generate revenues from fans by the sale of the rights to a broadcasting company, which in turn charges its viewers for the broadcast. $^{9}$

The parameter $m_{i}^{f}$ characterizes the market size of club $i$. We assume that club 1 is the large club, with a higher drawing potential, and as a result, a bigger fan base than the small club 2, such that $m_{1}^{f}>m_{2}^{f}$. Furthermore, the parameter $m^{s}$ represents the total market potential of the sponsors, or, in the case of a binding quota for sponsoring defined by the league, the sponsors' bounded market potential. ${ }^{10}$

The network externalities that operate from the fan market to the sponsor market are referred to as "fan-related network externalities" and are denoted by $n^{f} \in[0,1)$. We assume that the fan-related network externalities are positive because more fans imply more publicity and thus have a positive effect on the demand in the sponsor market. On the other hand, the network externalities that operate from the sponsor market to the fan market are referred to as "sponsor-related network externalities" and are denoted by $n^{s} \in(-1,1)$. Thus, we allow for positive or negative sponsor-related network externalities. However, we assume that the positive fan-related network externalities are at least as strong as the sponsor-related network externalities in absolute values, i.e., $n^{f} \geq\left|n^{s}\right|$. The possibly positive (even though small) effect of advertising on consumers (see, e.g., Nelson 1974 and Kotowitz/Mathewson 1979) reduces the negative sponsorrelated network externalities such that the assumption $n^{f} \geq\left|n^{s}\right|$ is reasonable. ${ }^{11}$

8 For the sake of completeness, we define the demand function of the sponsors $q_{i}^{s}$ to be zero in the case that there are no fans, i. e., $q_{i}^{f}=0$. However, note that $q_{i}^{f}=0$ will never be an equilibrium outcome.

9 In a first approach, our model includes the media indirectly as a lever for higher fan attendance. In further research, the media sector could be modeled as a third market side.

${ }^{10}$ Note that the parameter $m^{s}$ has no subscript, because we assume that there is only one homogeneous group of sponsors in the league offering advertisements to the two types of clubs. The introduction of a club-specific sponsor with market potential $m_{i}^{s}$ at club $i$ would not change the results qualitatively.

${ }^{11}$ A potentially negative externality derived from advertisements could be that fans want to watch sports events, not advertisements. In the case where the actual sports event is adapted to commercial requirements, e.g., special advertisement breaks, this aspect becomes even more obvious. For further discussion of this aspect, see Becker and Murphy (1993), Depken and Wilson (2004) and Reisinger et al. (2009). 
In general, network externalities can be illustrated by a displacement of the demand functions $q_{i}^{f}$ and $q_{i}^{s}$. In this respect, stronger network externalities induce stronger displacement of the corresponding demand functions. The combined network effects from fans and sponsors, denoted by $\eta$ are given by $\eta \equiv n^{f}+n^{s}$. A higher $n^{f}$ implies that the positive fan-related network externalities are relatively more important than the sponsor-related network externalities, such that the combined network effects increase. Similarly, a higher $n^{s}$ (i. e., either weaker negative or stronger positive sponsor-related network externalities) results in stronger combined network effects. By assuming that $n^{f} \geq\left|n^{s}\right|$ the combined network effects $\eta$ are not smaller than zero - i.e., $\eta \in[0,2)$. Consequently, $\eta>0$ describes a situation with positive combined network effects in which the positive fan-related network externalities are stronger than the sponsor-related network externalities in absolute values. If $\eta=0$ then the combined network effects equal zero. In this case, we have either a situation without network externalities (i.e., $n^{f}=n^{s}=0$ ) or a situation with equalized network externalities in which both individual network externalities are equal in terms of absolute values (i.e., $n^{f}=-n^{s}$ ).

Finally, the parameter $\theta_{i}$ denotes the quality of the competition between club $i$ against club $j$ and is specified below by equation (5). We assume that a higher quality of the the event (competition of the clubs) has a positive effect on fan demand, but at the same time, it has also a positive impact on sponsor demand (i.e., $\partial q_{i}^{s} / \partial \theta_{i}=$ $\left.p_{i}^{s} / \theta_{i}^{2}+n^{f}\left(\partial q_{i}^{f} / \partial \theta_{i}\right)>0\right)$ : there is a positive effect $\partial q_{i}^{f} / \partial \theta_{i}>0$ through more fans and a positive leverage effect $p_{i}^{s} / \theta_{i}^{2}>0$, because a high quality event draws a larger audience. The media serve as an additional lever, increasing sponsors' exposure to consumers. ${ }^{12}$ Consequently, sponsors' demand increases through a higher quality via more media exposure (Borland/MacDonald 2003 and Farrelly/Quester 2003).

\subsection{The quality of the competition}

We assume that the quality of the competition $\theta_{i}$ depends on two factors: the probability of club $i$ 's success and the uncertainty of outcome. Following Dietl et al. (2009) and Lang et al. (2011), we further assume that both factors enter the quality function as a sum with equal weights. ${ }^{13}$

We measure the probability of club $i$ 's success by the win percentage $w_{i}$ of this club. The win percentage, in turn, is characterized by the contest-success function (CSF), which maps the vector $\left(x_{i}, x_{j}\right)$ of talent investment into probabilities for each club. We apply the Tullock CSF, which is the most widely used functional form of a CSF in sporting contests, and we thus define the win percentage $w_{i}$ of club $i$ as ${ }^{14}$

$$
w_{i}\left(x_{i}, x_{j}\right)=\frac{x_{i}}{x_{i}+x_{j}}
$$

\footnotetext{
12 According to Grohs et al. (2004) sponsors aim to maximize their media presence and connect the image of their products to the image of the sports club brand in order to increase the demand for their goods and services.

${ }^{13}$ We will see below that this specification of the quality function gives rise to a quadratic revenue function widely used in the sports economic literature.

${ }^{14}$ This logit CSF for imperfectly discriminating contests was generally introduced by Tullock (1980) and it was subsequently axiomatized by Skaperdas (1996) and Clark and Riis (1998). An alternative functional form would be the probit CSF (Lazear/Rosen 1981; Dixit 1987), the difference-form CSF (Hirshleifer 1989) and the value weighted CSF (Runkel 2006). See Dietl et al. (2008) and Fort and Winfree (2009) for studies concerning the effect of the discriminatory power in the CSF.
} 
where $x_{i} \geq 0$ characterizes the talent investments of club $i$. We define $w_{i}\left(x_{i}, x_{j}\right):=1 / 2$ if $x_{i}=x_{j}=0$. Given that the win percentages must sum up to unity, we obtain the addingup constraint: $w_{j}=1-w_{i}$. Following Szymanski (2004), we adopt the "Contest-Nash conjectures" and compute the derivative of equation (3) as $\partial w_{i} / \partial x_{i}=x_{j} /\left(x_{i}+x_{j}\right)^{2}$.

The uncertainty of outcome is measured by the competitive balance in the league. Following Szymanski (2003), Dietl and Lang (2008), and Vrooman (2008), we specify competitive balance $C B$ by the product of the win percentages, i.e.,

$$
C B\left(x_{i}, x_{j}\right)=w_{i}\left(x_{i}, x_{j}\right) \cdot w_{j}\left(x_{i}, x_{j}\right)=\frac{x_{i} x_{j}}{\left(x_{i}+x_{j}\right)^{2}} .
$$

Note that competitive balance attains its maximum of $1 / 4$ for a completely balanced league in which both clubs invest the same amount in talent such that $w_{1}=w_{2}=1 / 2$. A less balanced league is then characterized by a lower value of $C B$.

With the specification of the win percentage given by equation (3) and competitive balance given by equation (4), club $i$ 's quality function $\theta_{i}$ as described above is derived as ${ }^{15}$

$$
\theta_{i}\left(x_{i}, x_{j}\right)=w_{i}\left(x_{i}, x_{j}\right)+w_{i}\left(x_{i}, x_{j}\right)\left[1-w_{i}\left(x_{i}, x_{j}\right)\right]=\frac{x_{i}\left(x_{i}+2 x_{j}\right)}{\left(x_{i}+x_{j}\right)^{2}} .
$$

A higher win percentage $w_{i}$ of club $i$ increases the quality of the competition $\theta_{i}$, albeit at a decreasing rate, which reflects the impact of competitive balance on the quality of the competition, i.e., $\partial \theta_{i} / \partial w_{i}>0$ and $\partial^{2} \theta_{i} / \partial w_{i}^{2}<0 .{ }^{16}$

\subsection{Derivation of club revenues, costs and profits}

Each club generates its own revenues such that total revenue $R_{i}$ of club $i$ is given by the sum of fan-related revenue $p_{i}^{f} q_{i}^{f}$ and sponsor-related revenue $p_{i}^{s} q_{i}^{s}$ :

$$
R_{i}=p_{i}^{f} q_{i}^{f}+p_{i}^{s} q_{i}^{s}=\left[\left(m_{i}^{f}-q_{i}^{f}+n^{s} q_{i}^{s}\right) q_{i}^{f}+\left(m^{s}-q_{i}^{s}+n^{f} q_{i}^{f}\right) q_{i}^{s}\right] \cdot \theta_{i}
$$

with $\theta_{i}=2 w_{i}\left(x_{i}, x_{j}\right)-w_{i}\left(x_{i}, x_{j}\right)^{2}$. This club-specific revenue function, which is quadratic in the win percentage, is widely used in the sports economics literature. For instance, our revenue is consistent with the revenue functions used in Szymanski (2003: 1164). Moreover, note that club $i$ 's revenues increase with the quality of the competition $\theta_{i}$.

By assuming a competitive labor market and following the sports economic literature, the market clearing cost of a unit of talent, denoted by $c$, is the same for every club. The cost function of club $i$ is thus given by $C\left(x_{i}\right)=c x_{i}$, where $c$ is the marginal unit cost of talent.

${ }^{15}$ An alternative would be to specify quality as $\theta_{i}=\mu w_{i}+w_{i}\left(1-w_{i}\right)$ where $\mu>0$ could allow the relative importance of the two components of the quality function to shift. A low $\mu$ would characterize a situation where fans have a high preference for competitive balance and a low preference for own team winning. However, this specification qualitatively yields the same results but would make the notation and calculations significantly more complicated without adding any new insights.

${ }^{16}$ For studies of competitive balance in sports leagues, see, e.g., Fort and Lee (2007) and Fort and Quirk (2011). 
The profit function of club $i$ is then given by revenues minus costs and yields

$$
\pi_{i}\left(x_{i}, x_{j}\right)=R_{i}\left(w_{i}\left(x_{i}, x_{j}\right)\right)-C\left(x_{i}\right) .
$$

\section{Equilibrium analysis}

In the first stage, clubs decide on their investments in playing talent, considering the cost of talent and its effect on their win percentage. In the second stage, given the quality of the competition as determined in stage 1 , clubs charge prices for fans and sponsors taking into account the network externalities. Then, fans and sponsors make their decisions. We apply backward induction to solve for the subgame-perfect equilibria in this two-stage game.

\subsection{Stage 2}

In this subsection, we characterize the point at which the pricing for fans and sponsors under network externalities is optimal such that clubs obtain maximum revenue. Clubs will take into account the relatedness of the fan and sponsor market and thus consider the consequences of the two distinct network externalities on the pricing decisions and demand functions. Formally, club $i=\{1,2\}$ maximizes its revenue $R_{i}=p_{i}^{f} q_{i}^{f}+p_{i}^{s} q_{i}^{s}$ in stage 2 by taking the investment decisions made in stage 1 as given. The equilibrium in prices and quantities in stage 2 is derived in the next lemma.

\section{Lemma 1}

In stage 2, equilibrium prices and quantities for fans and sponsors of club $i$ are given by

$$
\begin{aligned}
& \left(\widehat{p}_{i}^{f}, \widehat{q}_{i}^{f}\right)=\left(\frac{m_{i}^{f}\left(2-n^{f} \eta\right)+m^{s}\left(n^{s}-n^{f}\right)}{(2-\eta)(2+\eta)} \theta_{i}, \frac{2 m_{i}^{f}+m^{s} \eta}{(2-\eta)(2+\eta)}\right), \\
& \left(\widehat{p}_{i}^{s}, \widehat{q}_{i}^{s}\right)=\left(\frac{m_{i}^{f}\left(n^{f}-n^{s}\right)+m^{s}\left(2-n^{s} \eta\right)}{(2-\eta)(2+\eta)} \theta_{i}, \frac{m_{i}^{f} \eta+2 m^{s}}{(2-\eta)(2+\eta)}\right) .
\end{aligned}
$$

Proof. See Appendix A1.

In equilibrium, fans will demand the quantity represented by $\widehat{q}_{i}^{f}$ and are willing to pay the price represented by $\widehat{p}_{i}^{f}$. Correspondingly, the sponsors will demand $\widehat{q}_{i}^{s}$ and pay $\widehat{p}_{i}^{s}$ for each unit of advertisement in equilibrium. ${ }^{17}$ In the next lemma, we derive how equilibrium quantities and prices react to changes in the network externalities.

\section{Lemma 2}

(i) Equilibrium quantities for fans and sponsors of club $i$ increase with $n^{f}$ and $n^{s}$, i.e., $\partial \widehat{q}_{i}^{\mu} / \partial n^{f}>0$ and $\partial \hat{q}_{i}^{\mu} / \partial n^{s}>0$ for $\mu \in\{f, s\}$.

(ii) Given a certain quality of the competition $\theta_{i}$, equilibrium prices for fans (sponsors) of club $i$ decrease (increase) with stronger fan-related network externalities: i.e., $\partial \widehat{p}_{i}^{f} / \partial n^{f}<0\left(\partial \widehat{p}_{i}^{s} / \partial n^{f}>0\right)$. The opposite holds true for weaker negative or stronger positive sponsor-related network externalities on the prices for fans (sponsors): i.e., $\partial \widehat{p}_{i}^{f} / \partial n^{s}>0\left(\partial \widehat{p}_{i}^{s} / \partial n^{s}<0\right)$.

Proof. See Appendix A2.

${ }^{17}$ Note that if the market potential of the sponsors is larger than that of the fans of club $i$, i. e., $m^{s}>m_{i}^{f}$, we must bound $m^{s}$ from above such that $m^{s}<\bar{m}^{s} \equiv \frac{m_{i}^{f}\left(2-n^{f} \eta\right)}{n^{f}-n^{s}}$ in order to guarantee that $\widehat{p}_{i}^{f}>0$. 
In line with well-established results from the literature on two-sided markets (Armstrong 2006; Kaiser/Wright 2006; Rochet/Tirole 2006), Part (i) of the lemma shows that the stronger are the positive fan-related network externalities $n^{f}$, the higher is the equilibrium quantity demanded by fans and sponsors. If there is a disutility of the sponsors' advertisements for fans $\left(n^{s}<0\right)$, then the equilibrium quantities demanded by fans and sponsors decrease with stronger, i.e., more negative sponsor-related network externalities. If, on the other hand, $n^{s}>0$, then the equilibrium quantities demanded by fans and sponsors increase with stronger, i.e., more positive sponsor-related network externalities. It follows that the equilibrium demands $\widehat{q}_{i}^{s}$ and $\widehat{q}_{i}^{f}$ are higher in a situation in which the combined network effects are positive than in a situation in which the combined network effects are zero. Ceteris paribus, an increase in $n^{s}$ (i. e., either weaker negative or stronger positive sponsor-related network externalities) yields increased combined network effects and thus leads to an increase in the demand of fans. In combination with the positive fan-related network externalities, this induces an increase in demand on the part of sponsors.

Part (ii) of the lemma is also in line with the literature on two-sided markets and shows that given a certain quality of the competition $\theta_{i}$, the equilibrium price $\widehat{p}_{i}^{f}$ for the fans of club $i$ is lower and the equilibrium price $\widehat{p}_{i}^{s}$ for the sponsors is higher, the stronger are the positive fan-related network externalities $n^{f}$. Relatively stronger fan-related network externalities induce an increase in the demand function of the sponsors and yield, ceteris paribus, an increase in the prices for sponsors. The opposite holds true for weaker negative or stronger positive sponsor-related network externalities. Hence, if club $i$ decreases the price for the market with the stronger positive network externalities (in our model the fan market), it enhances the positive effect on revenues (Armstrong 2006).

It follows that due to the positive network externalities exerted by the fans on the sponsors, a revenue-maximizing club has an incentive to keep prices low on the market with the positive network externalities (fan market), whereas in the market with relatively weaker positive or even negative network externalities (sponsor market), it has an incentive to charge higher prices. We derive that equilibrium prices for fans (sponsors) are lower (higher) in a situation with positive combined network effects than in a situation in which combined network effects equal zero.

By substituting equilibrium prices and quantities of fans and sponsors from (8) and (9) in the revenue function (6), we compute the revenue of club $i$ as ${ }^{18}$

$$
\widehat{R}_{i}=\kappa_{i} \cdot \theta_{i}=\kappa_{i} \frac{x_{i}\left(x_{i}+2 x_{j}\right)}{\left(x_{i}+x_{j}\right)^{2}},
$$

with

$$
\kappa_{i} \equiv \frac{\left(m_{i}^{f}\right)^{2}+\left(m^{s}\right)^{2}+m_{i}^{f} m^{s} \eta}{(2-\eta)(2+\eta)} .
$$

In the next lemma, we derive some useful properties of the sponsor- and fan-related revenue function $\kappa_{i}$, which will be exploited in the subsequent analysis.

${ }^{18}$ The revenue function given by (10) satisfies the properties of the revenue function proposed by Szymanski and Késenne (2004: 168). 


\section{Lemma 3}

We consider $\kappa_{i}(\eta)$ as a function of the combined network externalities $\eta$ and derive the following properties: $\kappa_{1}(\eta)>\kappa_{2}(\eta)$ and $\partial \kappa_{1}(\eta) / \partial \eta>\partial \kappa_{2}(\eta) / \partial \eta>0$.

Proof. Straightforward and therefore omitted.

It follows from Lemma 3 that given a certain quality of competition equal for both clubs (i.e., $\theta_{1}=\theta_{2}$ ), the sponsor- and fan-related revenue of the large club will be higher than the revenue of the small club. Moreover, sponsor- and fan-related revenues for both types of clubs increase with stronger combined network effects, where the increase is stronger for the large club than for the small club.

\subsection{Stage 1}

In stage 1 , club $i$ maximizes its profits by anticipating the decisions made in stage 2 . By substituting club revenues (10) into the profit function (7), we derive the maximization problem of club $i$ in stage 1 as

$$
\max _{x_{i} \geq 0}\left\{\pi_{i}=\widehat{R}_{i}\left(x_{i}, x_{j}\right)-c x_{i}\right\}=\left(\frac{\left(m_{i}^{f}\right)^{2}+\left(m^{s}\right)^{2}+m_{i}^{f} m^{s} \eta}{(2-\eta)(2+\eta)}\right) \frac{x_{i}\left(x_{i}+2 x_{j}\right)}{\left(x_{i}+x_{j}\right)^{2}}-c x_{i} .
$$

The first-order conditions for this maximization problem yield ${ }^{19}$

$$
\frac{\partial \pi_{i}}{\partial x_{i}}=\left(\frac{\left(m_{i}^{f}\right)^{2}+\left(m^{s}\right)^{2}+m_{i}^{f} m^{s} \eta}{(2-\eta)(2+\eta)}\right) \frac{2 x_{j}^{2}}{\left(x_{i}+x_{j}\right)^{3}}-c=0 .
$$

Solving this system of equations, yields the equilibrium talent investments of club $i$ in stage 1 as

$$
\widehat{x}_{i}=\frac{2 \kappa_{i} \kappa_{j}\left[\kappa_{i}\left(\kappa_{i}+3 \kappa_{j}\right)-\left(\kappa_{i} \kappa_{j}\right)^{1 / 2}\left(3 \kappa_{i}+\kappa_{j}\right)\right]}{c\left(\kappa_{i}-\kappa_{j}\right)^{3}} .
$$

Both types of clubs invest a positive amount $\widehat{x}_{i}>0$ in playing talent. Moreover, the large club invests more in talent than the small club (i.e., $\widehat{x}_{1}>\widehat{x}_{2}$ ) because the marginal revenue of talent investments is higher for the former type of club due to the larger market potential of its fans. ${ }^{20}$ Note that the investments of both clubs are influenced by the network externalities exerted by fans and sponsors. Again, the extent to which fans and sponsors indirectly influence each other determines the decision of each club to invest in playing talent.

Substituting the equilibrium investments (13) into the CSF (3) yields the following equilibrium win percentages:

$$
\left(\widehat{w}_{1}, \widehat{w}_{2}\right)=\left(\frac{\kappa_{1}}{\kappa_{1}+\left(\kappa_{1} \kappa_{2}\right)^{1 / 2}}, \frac{\kappa_{2}}{\kappa_{2}+\left(\kappa_{1} \kappa_{2}\right)^{1 / 2}}\right) .
$$

By analyzing the impact of network externalities on the win percentages, we can establish the following proposition.

\footnotetext{
${ }^{19}$ It is easy to verify that the second-order conditions for a maximum are satisfied.

${ }^{20}$ See Buraimo et al. (2007), who analyze how playing success is linked to market size in practice.
} 


\section{Proposition 1}

Stronger combined network effects $\eta$ induce the large (small) club to decrease (increase) its win percentage in equilibrium and thus produce a more balanced league if and only if the market potential of the sponsors is sufficiently small. Formally, $\partial \widehat{w}_{1} / \partial \eta<0$ and $\partial \widehat{w}_{2} / \partial \eta>0 \Leftrightarrow m^{s}<\widehat{m}^{s} \equiv\left(m_{1}^{\prime} m_{2}^{f}\right)^{1 / 2}$.

Proof. See Appendix A3.

The proposition shows that with a sufficiently small market potential of the sponsors, i.e., $m^{s}<\widehat{m}^{s}$, the win percentage of the large (small) club decreases (increases) with stronger positive fan-related network externalities. Weaker negative or stronger positive sponsor-related network externalities yield the same result. The intuition behind this result is as follows. Stronger combined network effects have a positive impact on marginal revenue of both clubs such that both clubs will increase their investment levels. To determine which club increases its investments more strongly, we have to analyze the relationship between fans' market sizes and the sponsor's market potential. The difference in market sizes for the two clubs regarding their fan base yields that sponsor-related revenues are relatively more important to the small club than to the large club. It follows that the marginal impact on club revenues of stronger combined network effects is greater for the small club than for the large club.

As a result, the small club increases its investment in talent stronger than the large club as combined network effects increase. For the large club, the opposite rationale holds. In equilibrium, the large club increases its investment level less strongly than the small club, thereby decreasing its win percentage. Consequently, with stronger combined network externalities competitive balance increases. Thus, a league in which the positive fan-related network externalities are stronger than the sponsor-related network externalities (in absolute value) may be characterized by a higher degree of competitive balance than a league in which combined network effects are zero. For a sufficiently large market potential of the sponsors, i. e., $m^{s}>\widehat{m}^{s}$, the opposite holds true. In this case, competitive balance decreases if combined network effects increase.

Furthermore, note that the quality of the competition $\widehat{\theta}_{i}$ in equilibrium can be expressed in terms of $\kappa_{i}$ as

$$
\widehat{\theta}_{i}=\widehat{w}_{i}+\widehat{w}_{i} \widehat{w}_{j}=\frac{\kappa_{i}\left(2 \kappa_{j}+\left(\kappa_{i} \kappa_{j}\right)^{1 / 2}\right)}{\left(\kappa_{i}+\left(\kappa_{i} \kappa_{j}\right)^{1 / 2}\right)\left(\kappa_{j}+\left(\kappa_{i} \kappa_{j}\right)^{1 / 2}\right)} .
$$

We derive that stronger combined network effects imply a lower (higher) quality of competition for the large (small) club if and only if the market potential of the sponsors is sufficiently small. Formally, $\left(\partial \widehat{\theta}_{1} / \partial \eta<0\right.$ and $\left.\partial \widehat{\theta}_{2} / \partial \eta>0\right) \Leftrightarrow m^{s}<\widehat{m}^{s}$. Because the quality function for club $i$ is an increasing function in the win percentage $w_{i}$, the intuition is as follows. As we know from Proposition 1, a more balanced (unbalanced) league emerges in the case of sufficiently low (high) market potential on the part of the sponsors yielding a lower (higher) win percentage of the large club and a higher (lower) win percentage for the small club. It follows that the quality of competition for the large club decreases, while it increases for the small club if and only if $m^{s}<\widehat{m}^{s}$.

Substituting the equilibrium investments (13) in the profit function (7) yields the following equilibrium profits of club $i$ 


$$
\widehat{\pi}_{i}=\frac{\kappa_{i}^{2}\left[\kappa_{i}\left(2 \kappa_{j}+\left(\kappa_{i} \kappa_{j}\right)^{1 / 2}\right)-3 \kappa_{j}\left(\kappa_{i} \kappa_{j}\right)^{1 / 2}\right]}{\left(\kappa_{i}-\kappa_{j}\right)\left(\kappa_{i}+\left(\kappa_{i} \kappa_{j}\right)^{1 / 2}\right)\left(\kappa_{j}+\left(\kappa_{i} \kappa_{j}\right)^{1 / 2}\right)} .
$$

The impact of network externalities on club profits is established in the following proposition.

\section{Proposition 2}

Stronger combined network effects yield an increase in profits for the small and the large club.

Proof. See Appendix A4.

The proposition shows that the profits of the small and the large club increase if the positive network externalities that operate from the fan market to the sponsor market increase (or equivalently, through a weaker impact by sponsors' advertisements on the fans). Thus, the two types of clubs benefit from stronger network effects. To see the intuition behind this result, remember that the profits of club $i$ in equilibrium are given by $\widehat{\pi}_{i}=\kappa_{i} \widehat{\theta}_{i}-c \widehat{x}_{i}$, and hence, the partial derivatives with respect to combined network effects $\eta$ yield $\partial \widehat{\pi}_{i} / \partial \eta=\left(\partial \kappa_{i} / \partial \eta\right) \cdot \widehat{\theta}_{i}+\kappa_{i} \cdot\left(\partial \widehat{\theta}_{i} / \partial \eta\right)-c \cdot\left(\partial \widehat{x}_{i} / \partial \eta\right)$.

On the one hand, stronger combined network effects imply a higher investment level in playing talent such that both types of clubs face higher costs. On the other hand, stronger combined network effects increase sponsor-related and fan-related revenues $\kappa_{i}$ such that club revenues for both types of clubs increase. The higher club revenues compensate for the higher costs, and thus, club profits increase. It should be noted that the positive effect on club revenues due to stronger combined network effects holds true even though the quality of the competition $\widehat{\theta}_{i}$ will decrease for the large (small) club if the market potential $m^{s}$ of the sponsors is sufficiently small (large).

\section{Further Implications and Discussion}

\subsection{Competitive balance and network externalities}

Research on competitive balance has not considered the influence of network effects so far, i.e., the parameter $\eta$ has been assumed to be zero. By integrating the existence of network effects into models of sports leagues, new policy measures for leagues and their governing bodies emerge. For example, Proposition 1 suggests that network externalities positively affect competitive balance when there is a limit on sponsoring activities. In particular, if sponsors only dispose of a limited quota for advertisements $m^{s}<\widehat{m}^{s}$, competitive balance increases through stronger network externalities that operate from fans to sponsors (or equivalently, through a weaker impact by sponsors' advertisements on the fans).

The league and its clubs cannot manipulate the strength of the network externalities. However, by controlling the market potential of the sponsors, they can make sure that the network externalities operate in the desired direction. The market potential of the sponsors is thus a crucial parameter to control the competitive balance in our league model. This result will be emphasized in the next proposition.

Proposition 3

Competition in the league becomes more balanced if the market potential $\mathrm{m}^{\mathrm{s}}$ of the sponsors increases. 
Proof. See Appendix A5.

The proposition shows that a possible measure for improving competitive balance is to increase the market potential of the sponsors. An increase in the market potential of the sponsors could be achieved, for instance, through an increase in the quota for the amount of advertisements set by the league. Under a quota on sponsoring one can imagine restrictions on where advertisements may be placed (e.g. jerseys) or on the specific types of companies that are allowed to appear as sponsors in a league.

The intuition behind the result in Proposition 3 is that clubs generate revenues from fans and sponsors, where the amount of sponsorship revenues also depends on the amount of fans affiliated with a certain club (see Lemma 1). In equilibrium, the revenues generated from the sponsors' advertisements are higher for the large club than for the small club due to the larger market potential from the fans of the large club. An increase in the quota for the amount of advertising for the sponsors increases both clubs' marginal revenues. Due to the decreasing returns to scale of sponsors' advertising, the increase in marginal revenue, however, is stronger for the small club than for the large club. It follows that the incentives to invest in playing talent are higher for the small club than for the large club. This relative difference causes the former type of club to increase its equilibrium talent investments more than the latter type of club. As a result, the win percentage of the large (small) club decreases (increases) and a more balanced league emerges.

\subsection{Revenue sharing and network externalities}

In this section, we analyze the effect of revenue sharing in the presence of network externalities. The sharing of revenues plays an important role in the redistribution of revenues and has long been accepted as an exemption from antitrust law. ${ }^{21}$ The basic idea of such a cross-subsidization policy is to guarantee a reasonable competitive balance in the league by redistributing revenues from large clubs to small clubs because large clubs have a higher revenue-generating potential than do small clubs (Atkinson et al. 1988; Késenne 2000a; Szymanski/Késenne 2004; Dietl et al. 2011). The current revenue-sharing schemes vary widely among professional sports leagues. The most prominent is possibly that operated by the National Football League (NFL), in which the visiting club receives 40 of the locally earned television and gate receipt revenue. Major League Baseball (MLB) has a revenue-sharing agreement whereby all the clubs in the American League put 34 of their locally generated revenue (gate, concessions, television, etc.) into a central pool, which is then divided equally among all the clubs.

We introduce a pool revenue-sharing arrangement into our model. Under a pool-sharing arrangement, club $i$ receives an $a$-share of its revenue $R_{i}$ and an $(1-a) / 2$-share of a league revenue pool $R_{i}+R_{j}$. The after-sharing revenues of club $i$, denoted by $R_{i}^{*}$, can be written as:

$$
R_{i}^{*}=a \widehat{R}_{i}+\frac{(1-a)}{2}\left(\widehat{R}_{i}+\widehat{R}_{j}\right)
$$

with $a \in(0,1]$. It should be noted that a higher parameter $a$ represents a league with a lower degree of redistribution. Hence, the case of $\alpha=1$ describes a league without

${ }^{21}$ Professional team sports leagues often find themselves under antitrust surveillance (Flynn/Gilbert 2001). According to Szymanski (2003), most revenue-sharing arrangements have not been challenged in the courts because revenue sharing is supposed to enhance competitive balance, and thus, is in the interest of the consumer. 
revenue-sharing, while the limiting case of $\alpha=0$ would characterize a league with equal revenue sharing.

The maximization problem of club $i$ is thus given by

$$
\max _{x_{i} \geq 0}\left\{R_{i}^{*}\left(x_{i}, x_{j}\right)=a \widehat{R}_{i}\left(x_{i}, x_{j}\right)+(1-a) \widehat{R}_{j}\left(x_{i}, x_{j}\right)-c x_{i}\right\} .
$$

By solving this maximization problem and analyzing the effect of revenue sharing on the equilibrium win percentages, we can establish the following proposition.

\section{Proposition 4}

In the presence of network externalities, revenue sharing always decreases the competitive balance in the league. Network externalities, however, mitigate the negative effect of revenue sharing on competitive balance if and only if the market potential $m^{s}$ of the sponsors is sufficiently small with $m^{s}<\widehat{m}^{s}$.

Proof. See Appendix A6.

In accordance to other contest models of sports leagues with profit-maximizing clubs (e.g., Szymanski/Késenne 2004; Grossmann et al. 2010), the proposition shows that revenue sharing produces a less balanced competition in a league in which positive network externalities operate from the fan market to the sponsor market, while negative network externalities operate from the sponsor market to the fan market. A higher degree of revenue sharing, i.e., a lower parameter $\alpha$, results in a higher win percentage for the large club and a lower win percentage for the small club.

The intuition behind this result is as follows. Revenue sharing has a negative effect on marginal revenue of both clubs in equilibrium. This so-called "dulling effect" is more pronounced for the underdog (small club) than for the dominant team (large club). Due to the logit formulation of the CSF, the (positive) marginal impact on the dominant team's revenues of a decrease in talent investment by the underdog is greater than the (positive) marginal impact on the underdog's revenues of a decrease in talent investment by the dominant team. As a result, the small club will reduce its investment level relatively more than the large club such that the league becomes less balanced through revenue sharing.

Network externalities, however, can mitigate the negative effect of revenue sharing on competitive balance. In particular, if the market potential of the sponsors is sufficiently small such that $m^{s}<\widehat{m}^{s}$ then stronger combined network effects reduce the differences between clubs in terms of win percentages and thus reduce the negative effect of revenue sharing on competitive balance. In the opposite case, i.e., $m^{s}>\widehat{m}^{s}$, network externalities even reinforce the dulling effect such that the negative impact of revenue sharing on competitive balance augments.

\section{Conclusion}

In this paper, we have developed a contest model of a professional team sports league with two market sides. The competition of the clubs is the platform between fans on one market side and sponsors on the other market side. Positive network externalities operate from the fan market to the sponsor market, and ambiguous network externalities operate from the sponsor market to the fan market. 
In line with the literature on two-sided markets, our analysis shows that a revenue-maximizing club has an incentive to keep prices low in the market with relatively stronger positive network externalities and charge a higher price in a market with relatively weaker positive or negative network externalities. In our model, low prices on the fan market enhance the positive effect on club revenues due to the positive network externalities that operate from the fan market to the sponsor market. An increase in the demand in the fan market leads (through positive fan-related network externalities) to an increase in the demand on the sponsor market. High prices in the market with positive network externalities would inhibit the positive effect on club revenues.

New and potentially important for the sports economics literature, we further derive that network externalities may crucially affect competitive balance in a sports league. In particular, we show that stronger combined network effects induce both clubs to increase their talent investments in equilibrium. If the market potential of the sponsors is sufficiently small, the increase in talent investments of the small club will be stronger than that of the large club because the small club benefits more from stronger network effects than the large club. As a result, the win percentage of the small club increases and the win percentage of the large club decreases in equilibrium, yielding a more balanced league. With the introduction of a revenue sharing arrangement, our model shows that network externalities can mitigate the negative effect of revenue sharing on competitive balance.

We conclude that it is important to incorporate network externalities into the analysis of team sports leagues. Depending on the market potential of the sponsors, theoretical analyses of sports leagues that do not take network externalities into account may under- or overestimate the actual level of competitive balance in a league. For instance, theoretical models without network externalities may suggest the implementation of measures to increase competitive balance, which may not be necessary because the league may already be optimally balanced. ${ }^{22}$ Finally, our model suggests that both types of clubs benefit from the presence of network externalities because club profits always increase with stronger combined network effects. This result holds true even though costs increase for both types of clubs due to higher talent investments. The higher club revenues, however, compensate for the higher costs, such that club profits always increase.

Our model may serve as a basic framework for the analysis of network effects in team sports leagues. There is a broad range of further applications and model extensions. For instance, it could be potentially fruitful to model the competition between the clubs not only on the pitch but also to attract fans and/or sponsors. In our current setting, the two clubs are essentially monopolistic platforms because each platform attracts fans and sponsors from different subsets. It would be interesting to see whether our results carry over to a setting with competing platforms. Another promising avenue for further research would be the extension of our model in order to conduct a welfare analysis in the framework of a sports league with network externalities. ${ }^{23}$ Even though the relevance of competitive balance is intuitively plausible, an exclusive focus on competitive balance would only be justified if the uncertainty of outcome hypothesis completely holds. If, on the other hand, social welfare does not monotonically increase as competitive balance increases, an exclusive focus on competitive balance would result in inefficient policy

\footnotetext{
22 See Fort and Quirk (2011), who analyze the optimal degree of competitive balance in a season ticket sports league.

${ }^{23}$ We are grateful to an anonymous referee for these two suggestions.
} 
conclusions. ${ }^{24}$ Finally, we encourage to introduce restrictions on player salaries (caps and floors) into our model. Payroll restrictions to improve competitive balance and control costs are common in professional team sports leagues all around the world. The implementation of such payroll restrictions in the model with network externalities could yield further implications for the governance of team sports leagues.

\section{Appendix}

\section{A1 Proof of Lemma 1}

In stage 2 , club $i$ maximizes its revenue $R_{i}=p_{i}^{f} q_{i}^{f}+p_{i}^{s} q_{i}^{s}$, by taking the investment decisions made in stage 1 as given. Formally, club $i$ solves the following maximization problem: ${ }^{25}$

$$
\max _{\left(q_{i}^{f}, q_{i}^{s}\right) \geq 0} R_{i}=p_{i}^{f} q_{i}^{f}+p_{i}^{s} q_{i}^{s}=\left[\left(m_{i}^{f}-q_{i}^{f}+n^{s} q_{i}^{s}\right) q_{i}^{f}+\left(m^{s}-q_{i}^{s}+n^{f} q_{i}^{f}\right) q_{i}^{s}\right] \theta_{i} .
$$

The reaction functions of fans and sponsors are derived as

$$
q_{i}^{f}\left(q_{i}^{s}\right)=\frac{1}{2}\left(m_{i}^{f}+\left(n^{f}+n^{s}\right) q_{i}^{s}\right) \text { and } q_{i}^{s}\left(q_{i}^{f}\right)=\frac{1}{2}\left(m^{s}+\left(n^{f}+n^{s}\right) q_{i}^{f}\right) .
$$

Note that there is a positive relationship between the quantities demanded by sponsors and fans in equilibrium if the combined network effects are positive, i.e., $n^{f}+n^{s}>0$.

Solving this system of reaction functions, yields the following equilibrium quantities for club $i$

$$
\widehat{q}_{i}^{f}=\frac{2 m_{i}^{f}+m^{s} \eta}{(2-\eta)(2+\eta)} \text { and } \widehat{q}_{i}^{s}=\frac{m_{i}^{f} \eta+2 m^{s}}{(2-\eta)(2+\eta)} .
$$

Substitution into prices $p_{i}^{f}=\left(m_{i}^{f}-\widehat{q}_{i}^{f}+n^{s} \widehat{q}_{i}^{s}\right) \theta_{i}$ and $p_{i}^{s}=\left(m^{s}-\widehat{q}_{i}^{s}+n^{f} \widehat{q}_{i}^{f}\right) \theta_{i}$ yields

$$
\widehat{p}_{i}^{f}=\frac{m_{i}^{f}\left(2-n^{f} \eta\right)+m^{s}\left(n^{s}-n^{f}\right)}{(2-\eta)(2+\eta)} \theta_{i} \text { and } \widehat{p}_{i}^{s}=\frac{m_{i}^{f}\left(n^{f}-n^{s}\right)+m^{s}\left(2-n^{s} \eta\right)}{(2-\eta)(2+\eta)} \theta_{i} \text {. }
$$

This completes the proof of the lemma.

\section{A2 Proof of Lemma 2}

(i) To show that equilibrium quantities $\left(\widehat{q}_{i}^{f}, \widehat{q}_{i}^{s}\right)$ for fans and sponsors of club $i$ increase (decrease) with stronger fan (sponsor) network effects, we compute

\footnotetext{
${ }^{24}$ Apart of the problems of proxying competitive balance, the empirical evidence on the effects of competitive balance onto demand remains ambiguous (Downward/Dawson 2000 and Szymanski 2003).

${ }^{25}$ In our setting it is an equivalent approach if clubs first maximize revenues with respect to quantities and then derive equilibrium prices or vice versa.
} 


$$
\frac{\partial \widehat{q}_{i}^{f}}{\partial n^{f}}=\frac{\partial \widehat{q}_{i}^{f}}{\partial n^{s}}=\frac{4 m_{i}^{f} \eta+m^{s}\left(4+\eta^{2}\right)}{[(2-\eta)(2+\eta)]^{2}}>0 \text { and } \frac{\partial \widehat{q}_{i}^{s}}{\partial n^{f}}=\frac{\partial \widehat{q}_{i}^{s}}{\partial n^{s}}=\frac{4 m^{s} \eta+m_{i}^{f}\left(4+\eta^{2}\right)}{[(2-\eta)(2+\eta)]^{2}}>0,
$$

for $m_{i}^{f}>0, m^{s}>0,1>n^{f} \geq\left|n^{s}\right| \geq 0$ and $\eta \in[0,2)$.

(ii) To show that, given a certain quality of the competition $\theta_{i}$, equilibrium prices $\widehat{p}_{i}^{f}$ for fans ( $\widehat{p}_{i}^{s}$ for sponsors) of club $i$ decrease (increase) with stronger fan-related network effects, we compute

$$
\begin{aligned}
& \frac{\partial \widehat{p}_{i}^{f}}{\partial n^{f}}=-\frac{m_{i}^{f}\left(4 n^{f}-n^{s} \eta^{2}\right)+m^{s}\left[4+\eta\left(n^{f}-3 n^{s}\right)\right]}{[(2-\eta)(2+\eta)]^{2}}<0, \\
& \frac{\partial \widehat{p}_{i}^{s}}{\partial n^{f}}=\frac{m^{s}\left(4 n^{f}-n^{s} \eta^{2}\right)+m_{i}^{f}\left[4+\eta\left(n^{f}-3 n^{s}\right)\right]}{[(2-\eta)(2+\eta)]^{2}}>0,
\end{aligned}
$$

for $m_{i}^{f}>0, m^{s}>0,1>n^{f} \geq\left|n^{s}\right| \geq 0$ and $\eta \in[0,2)$.

To show that, given a certain quality of the competition $\theta_{i}$, equilibrium prices $\widehat{p}_{i}^{f}$ for fans ( $\widehat{p}_{i}^{s}$ for sponsors) of club $i$ increase (decrease) with stronger sponsor-related network effects, we compute

$$
\begin{aligned}
& \frac{\partial \hat{p}_{i}^{f}}{\partial n^{s}}=\frac{m_{i}^{f}\left(4 n^{s}-n^{f} \eta^{2}\right)+m_{i}^{s}\left[4+\eta\left(n^{s}-3 n^{f}\right)\right]}{[(2-\eta)(2+\eta)]^{2}}>0, \\
& \frac{\partial \widehat{p}_{i}^{s}}{\partial n^{s}}=-\frac{m^{s}\left(4 n^{s}-n^{f} \eta^{2}\right)+m_{i}^{f}\left[4+\eta\left(n^{s}-3 n^{f}\right)\right]}{[(2-\eta)(2+\eta)]^{2}}<0,
\end{aligned}
$$

for $m_{i}^{f} \in\left[\frac{m^{s}\left(4 n^{s}-n^{f} \eta^{2}\right)}{\eta\left(3 n^{f}-n^{s}\right)-4}, \frac{m^{s}\left(4+\eta\left(3 n^{f}-n^{s}\right)\right)}{n^{f} \eta^{2}-4 n^{s}}\right], m^{s}>0,1>n^{f} \geq\left|n^{s}\right| \geq 0$ and $\eta \in[0,2)$. This completes the proof of the lemma.

\section{A3 Proof of Proposition 1}

To prove that stronger combined network effects induce the large (small) club to decrease (increase) its win percentage in equilibrium if and only if the market potential of the sponsors is sufficiently small, we proceed as follows. We write $\frac{\partial \kappa_{i}(\eta)}{\partial \eta}=\kappa_{i}^{\prime}(\eta)$. According to Lemma 3, we know that $\kappa_{1}(\eta)>\kappa_{2}(\eta)$ and $\kappa_{1}^{\prime}(\eta)>\kappa_{2}^{\prime}(\eta)>0$. Thus, we compute $\widehat{w}_{1} / \widehat{w}_{2}=\kappa_{1}(\eta) /\left[\kappa_{1}(\eta) \kappa_{2}(\eta)\right]^{1 / 2}>1$. Now, we will show that $\frac{\partial\left(w_{1} / w_{2}\right)}{\partial \eta}<0$ and thus $\frac{\partial w_{1}}{\partial \eta}<0$ and $\frac{\partial w_{2}}{\partial \eta}>0$ :

$$
\frac{\partial\left(\widehat{w}_{1} / \widehat{w}_{2}\right)}{\partial \eta}=\frac{\kappa_{1}(\eta)\left[\kappa_{1}^{\prime}(\eta) \kappa_{2}(\eta)-\kappa_{1}(\eta) \kappa_{2}^{\prime}(\eta)\right]}{2\left[\kappa_{1}(\eta) \kappa_{2}(\eta)\right]^{3 / 2}}<0 \Leftrightarrow \frac{\kappa_{1}(\eta)}{\kappa_{2}(\eta)}>\frac{\kappa_{1}^{\prime}(\eta)}{\kappa_{2}^{\prime}(\eta)} .
$$

With $\kappa_{i}(\eta)$ given by $(11)$, it holds

$$
\frac{\kappa_{1}(\eta)}{\kappa_{2}(\eta)}=\frac{\left(m_{1}^{f}\right)^{2}+\left(m^{s}\right)^{2}+m_{1}^{f} m^{s} \eta}{\left(m_{2}^{f}\right)^{2}+\left(m^{s}\right)^{2}+m_{2}^{f} m^{s} \eta} \text { and } \frac{\kappa_{1}^{\prime}(\eta)}{\kappa_{2}^{\prime}(\eta)}=\frac{\left(m_{1}^{f} \eta+2 m^{s}\right)\left(2 m_{1}^{f}+m^{s} \eta\right)}{\left(m_{2}^{f} \eta+2 m^{s}\right)\left(2 m_{2}^{f}+m^{s} \eta\right)} .
$$

We conclude that $\frac{\kappa_{1}(\eta)}{\kappa_{2}(\eta)}>\frac{\kappa_{1}^{\prime}(\eta)}{\kappa_{2}^{\prime}(\eta)} \Leftrightarrow m^{s}<\widehat{m}^{s}$. This completes the proof of the proposition. 


\section{A4 Proof of Proposition 2}

To prove that stronger combined network effects increase profits of the large and small club, we write the equilibrium profits of club $i$ as a function of $\eta$ with

$$
\widehat{\pi}_{i}(\eta)=\frac{\kappa_{i}(\eta)^{2}\left[-3 \kappa_{j}(\eta)\left[\kappa_{i}(\eta) \kappa_{j}(\eta)\right]^{1 / 2}+\kappa_{i}(\eta)\left(2 \kappa_{j}(\eta)+\left[\kappa_{i}(\eta) \kappa_{j}(\eta)\right]^{1 / 2}\right)\right]}{\left(\kappa_{i}(\eta)-\kappa_{j}(\eta)\right)\left(\kappa_{i}(\eta)+\left[\kappa_{i}(\eta) \kappa_{j}(\eta)\right]^{1 / 2}\right)\left(\kappa_{j}(\eta)+\left[\kappa_{i}(\eta) \kappa_{j}(\eta)\right]^{1 / 2}\right)}
$$

and compute the partial derivative with respect to the combined network effects $\eta$ as

$$
\frac{\partial \widehat{\pi}_{i}(\eta)}{\partial \eta}=\frac{\kappa_{i}(\eta)\left[4\left[\kappa_{i}(\eta) \kappa_{j}(\eta)\right]^{1 / 2} \kappa_{i}^{\prime}(\eta)+\left[\kappa_{i}(\eta)+6 \kappa_{j}(\eta)\right] \kappa_{i}^{\prime}(\eta)-3 \kappa_{i}(\eta) \kappa_{j}^{\prime}(\eta)\right]}{\left(\kappa_{i}(\eta)+\kappa_{j}(\eta)+2\left[\kappa_{i}(\eta) \kappa_{j}(\eta)\right]^{1 / 2}\right)^{2}} .
$$

To prove that $\frac{\partial \widehat{\pi}_{i}}{\partial \eta}>0$, it suffices to show that $\left[\kappa_{i}(\eta)+6 \kappa_{j}(\eta)\right] \kappa_{i}^{\prime}(\eta)-3 \kappa_{i}(\eta) \kappa_{j}^{\prime}(\eta)>0$ because then the numerator is positive. ${ }^{26}$ We derive

$$
\left[\kappa_{i}(\eta)+6 \kappa_{j}(\eta)\right] \kappa_{i}^{\prime}(\eta)>3 \kappa_{i}(\eta) \kappa_{j}^{\prime}(\eta) \Leftrightarrow \frac{\kappa_{i}(\eta)+6 \kappa_{j}(\eta)}{3 \kappa_{i}(\eta)}>\frac{\kappa_{j}^{\prime}(\eta)}{\kappa_{i}^{\prime}(\eta)}
$$

With $\kappa_{i}(\eta)$ given by (11), this inequality translates for club 1 into

$$
a_{1}(\eta) \equiv \frac{m_{1}^{f}\left(m_{1}^{f}+m^{s} \eta\right)+6 m_{2}^{f}\left(m_{2}^{f}+m^{s} \eta\right)+7 m^{s}}{3\left[m_{1}^{f}\left(m_{1}^{f}+m^{s} \eta\right)+\left(m^{s}\right)^{2}\right]}>\frac{\left(2 m^{s}+m_{2}^{f} \eta\right)\left(2 m_{2}^{f}+m^{s} \eta\right)}{\left(2 m^{s}+m_{1}^{f} \eta\right)\left(2 m_{1}^{f}+m^{s} \eta\right)} \equiv \beta_{1}(\eta)
$$

and for club 2 into

$$
a_{2}(\eta) \equiv \frac{6 m_{1}^{f}\left(m_{1}^{f}+m^{s} \eta\right)+m_{2}^{f}\left(m_{2}^{f}+m^{s} \eta\right)+7 m^{s}}{3\left[m_{2}^{f}\left(m_{2}^{f}+m^{s} \eta\right)+\left(m^{s}\right)^{2}\right]}>\frac{\left(2 m^{s}+m_{1}^{f} \eta\right)\left(2 m_{1}^{f}+m^{s} \eta\right)}{\left(2 m^{s}+m_{2}^{f} \eta\right)\left(2 m_{2}^{f}+m^{s} \eta\right)} \equiv \beta_{2}(\eta)
$$

Next, we derive the following properties of $\alpha_{i}(\eta)$ and $\beta_{i}(\eta)$ with $i \in\{1,2\}$ :

$$
\begin{aligned}
& a_{i}(\eta) \in C^{1} \text { and } \beta_{i}(\eta) \in C^{1} \\
& \frac{\partial a_{1}(\eta)}{\partial \eta}>0 \Leftrightarrow m_{1}^{f} m_{2}^{f}>\left(m^{s}\right)^{2}, \frac{\partial \beta_{1}(\eta)}{\partial \eta}>0 \Leftrightarrow m_{1}^{f} m_{2}^{f}<\left(m^{s}\right)^{2} \text { and } \\
& \frac{\partial a_{2}(\eta)}{\partial \eta}>0 \Leftrightarrow m_{1}^{f} m_{2}^{f}<\left(m^{s}\right)^{2}, \frac{\partial \beta_{2}(\eta)}{\partial \eta}>0 \Leftrightarrow m_{1}^{f} m_{2}^{f}>\left(m^{s}\right)^{2} \\
& a_{1}(0)=\frac{7}{3}-\frac{2\left(m_{1}^{f}-m_{2}^{f}\right)\left(m_{1}^{f}+m_{2}^{f}\right)}{\left(m_{1}^{f}\right)^{2}+\left(m^{s}\right)^{2}}>\frac{m_{2}^{f}}{m_{1}^{f}}=\beta_{1}(0) \text { and }
\end{aligned}
$$

\footnotetext{
${ }^{26}$ Note that the numerator would be positive for a less restrictive condition.
} 


$$
\begin{aligned}
& \lim _{\eta \rightarrow 2} \alpha_{1}(\eta)=\frac{m_{1}^{f}\left(m_{1}^{f}+2 m^{s}\right)+6 m_{2}^{f}\left(m_{2}^{f}+2 m^{s}\right)+7 m^{s}}{3\left(m_{2}^{f}+m^{s}\right)^{2}}>\frac{\left(m^{s}+m_{1}^{f}\right)^{2}}{\left(m^{s}+m_{2}^{f}\right)^{2}}=\lim _{\eta \rightarrow 2} \beta_{1}(\eta) \\
& a_{2}(0)=\frac{7}{3}-\frac{2\left(m_{2}^{f}-m_{1}^{f}\right)\left(m_{1}^{f}+m_{2}^{f}\right)}{\left(m_{1}^{f}\right)^{2}+\left(m^{s}\right)^{2}}>\frac{m_{1}^{f}}{m_{2}^{f}}=\beta_{2}(0) \text { and } \\
& \lim _{\eta \rightarrow 2} \alpha_{2}(\eta)=\frac{6 m_{1}^{f}\left(m_{1}^{f}+2 m^{s}\right)+m_{2}^{f}\left(m_{2}^{f}+2 m^{s}\right)+7 m^{s}}{3\left(m_{1}^{f}+m^{s}\right)^{2}}>\frac{\left(m^{s}+m_{2}^{f}\right)^{2}}{\left(m^{s}+m_{1}^{f}\right)^{2}}=\lim _{\eta \rightarrow 2} \beta_{2}(\eta)
\end{aligned}
$$

From (20), (21), (22), and (23) we derive that inequalities (18) and (19) are satisfied for all $m_{i}^{f}>0, m^{s}>0,1>n^{f} \geq\left|n^{s}\right| \geq 0$ and $\eta \in[0,2)$. It follows that inequality (17) is satisfied such that club profits are increasing with stronger combined network effects. This completes the proof of the proposition.

\section{A5 Proof of Proposition 3}

To prove that a larger market potential $m^{s}$ of the sponsors increases the competitive balance in the league, we proceed as follows. We consider $\kappa_{i}\left(m^{s}\right)=\frac{\left(m_{i}^{f}\right)^{2}+\left(m^{s}\right)^{2}+m_{i}^{f} m^{s} \eta}{(2-\eta)(2+\eta)}$ as a function of $m^{s}$ and write $\frac{\partial \kappa_{i}\left(m^{s}\right)}{\partial m^{s}}=\kappa_{i}^{\prime}\left(m^{s}\right)$. We derive the following properties:

$$
\begin{aligned}
& \kappa_{1}\left(m^{s}\right)-\kappa_{2}\left(m^{s}\right)=\frac{\left(m_{1}^{f}-m_{2}^{f}\right)\left(m_{1}^{f}+m_{2}^{f}+m^{s} \eta\right)}{(2-\eta)(2+\eta)}>0, \\
& \kappa_{i}^{\prime}\left(m^{s}\right)=\frac{m_{i}^{f} \eta+2 m^{s}}{(2-\eta)(2+\eta)}>0, \text { and } \kappa_{1}^{\prime}\left(m^{s}\right)>\kappa_{2}^{\prime}\left(m^{s}\right)
\end{aligned}
$$

for all $m_{1}^{f}>m_{2}^{f}>0, m^{s}>0$ and $\eta \in[0,2)$. We know that competitive balance can be expressed in terms of $\kappa_{i}\left(m^{s}\right)$ as $\widehat{w}_{1}=\frac{\kappa_{1}\left(m^{s}\right)}{\widehat{w}_{2}}=1$. Now, we will show that $\frac{\partial\left(\widehat{w}_{1} \widehat{w}_{2}\right)}{\partial m^{s}}<0$ and thus $\frac{\partial \widehat{w}_{1}}{\partial m^{s}}<0$ and $\frac{\partial \widehat{w}_{2}}{\partial m^{s}}>0$ :

$$
\frac{\partial\left(\widehat{w}_{1} / \widehat{w}_{2}\right)}{\partial m^{s}}=\frac{\kappa_{1}\left(m^{s}\right)\left[\kappa_{1}^{\prime}\left(m^{s}\right) \kappa_{2}\left(m^{s}\right)-\kappa_{1}\left(m^{s}\right) \kappa_{2}^{\prime}\left(m^{s}\right)\right]}{2\left[\kappa_{1}\left(m^{s}\right) \kappa_{2}\left(m^{s}\right)\right]^{3 / 2}}<0 \Leftrightarrow \frac{\kappa_{1}\left(m^{s}\right)}{\kappa_{2}\left(m^{s}\right)}>\frac{\kappa_{1}^{\prime}\left(m^{s}\right)}{\kappa_{2}^{\prime}\left(m^{s}\right)}
$$

We derive

$$
\frac{\kappa_{1}\left(m^{s}\right)}{\kappa_{2}\left(m^{s}\right)}=\frac{\left(m_{1}^{f}\right)^{2}+\left(m^{s}\right)^{2}+m_{1}^{f} m^{s} \eta}{\left(m_{2}^{f}\right)^{2}+\left(m^{s}\right)^{2}+m_{2}^{f} m^{s} \eta} \text { and } \frac{\kappa_{1}^{\prime}\left(m^{s}\right)}{\kappa_{2}^{\prime}\left(m^{s}\right)}=\frac{m_{1}^{f} \eta+2 m^{s}}{m_{2}^{f} \eta+2 m^{s}}
$$

and can show that $\frac{\kappa_{1}\left(m^{s}\right)}{\kappa_{2}\left(m^{s}\right)}>\frac{\kappa_{1}^{\prime}\left(m^{s}\right)}{\kappa_{2}^{\prime}\left(m^{s}\right)}$ holds for all $m^{s}>0$. We conclude that competitive balance increases with a larger market potential of the sponsors, i.e., $\frac{\partial\left(\widehat{w}_{1} / w_{2}\right)}{\partial m^{s}}<0$. This completes the proof of the proposition. 


\section{A6 Proof of Proposition 4}

The first-order conditions of the maximization problem (15) are derived as

$$
\frac{\partial R_{i}^{*}}{\partial x_{i}}=\alpha \frac{\partial \widehat{R}_{i}}{\partial w_{i}} \frac{\partial w_{i}}{\partial x_{i}}+\frac{1-a}{2}\left(\frac{\partial \widehat{R}_{i}}{\partial w_{i}} \frac{\partial w_{i}}{\partial x_{i}}+\frac{\partial \widehat{R}_{j}}{\partial w_{j}} \frac{\partial w_{j}}{\partial x_{i}}\right)-c=0 .
$$

It is easy to verify that the second-order conditions for a maximum are satisfied. By combining the first-order conditions of club $i$ and $j$, and using the adding-up constraint $\frac{\partial w_{i}}{\partial x_{i}}=-\frac{\partial w_{i}}{\partial x_{i}}$, we obtain

$$
\left[\alpha \frac{\partial \widehat{R}_{i}}{\partial w_{i}}-\frac{1-\alpha}{2}\left(\frac{\partial \widehat{R}_{j}}{\partial w_{j}}-\frac{\partial \widehat{R}_{i}}{\partial w_{i}}\right)\right] \frac{\partial w_{i}}{\partial x_{i}}=\left[\alpha \frac{\partial \widehat{R}_{j}}{\partial w_{j}}-\frac{1-a}{2}\left(\frac{\partial \widehat{R}_{i}}{\partial w_{i}}-\frac{\partial \widehat{R}_{j}}{\partial w_{j}}\right)\right] \frac{\partial w_{j}}{\partial x_{j}} .
$$

By using (3) and (10), and after some rearrangements, we find that in equilibrium $\left(\widehat{x}_{1}^{*}, \widehat{x}_{2}^{*}\right)$ it must hold

$$
\widehat{x}_{1}^{*}=\frac{(1-\alpha)\left(\kappa_{1}-\kappa_{2}\right)+\left[(1-\alpha)^{2}\left(\kappa_{1}^{2}+\kappa_{2}^{2}\right)+2 \kappa_{1} \kappa_{2}(1+\alpha(6+a)]^{1 / 2}\right.}{2(1+\alpha) \kappa_{2}} \widehat{x}_{2}^{*},
$$

with $\kappa_{i}, i \in\{1,2\}$ given by (11). It follows that the equilibrium win percentage of club $i$ is given by

$$
\widehat{w}_{i}^{*}=\frac{\kappa_{i}(1+3 a)+\kappa_{j}(1-\alpha)-\left[(1-a)^{2}\left(\kappa_{1}^{2}+\kappa_{2}^{2}\right)+2 \kappa_{1} \kappa_{2}(1+a(6+a)]^{1 / 2}\right.}{4 a\left(\kappa_{i}-\kappa_{j}\right)} .
$$

We further compute the partial derivative of $\widehat{w}_{1}^{*}$ with respect to $a$ at $a=1$ as $\left.\frac{\partial \widehat{w}_{1}^{\prime \prime}}{\partial a}\right|_{a=1}=-\frac{\kappa_{1}+\kappa_{2}-2 \sqrt{\kappa_{1} \kappa_{2}}}{4\left(\kappa_{1}-\kappa_{2}\right)}<0$, because $\kappa_{1}>\kappa_{2}$. We conclude that a higher degree of revenue sharing (i.e., a lower $a$ ) increases the win percentage of the large club 1 and consequently decreases the win percentage of the small club 2. As a result, competitive balance decreases which proves part (i) of the proposition.

To prove part (ii), we proceed as follows. We define $F(\eta)$ as the partial derivative of $\widehat{w}_{1}^{*}$ with respect to $a$ at $a=1$, i.e., $F(\eta):=\frac{\kappa_{1}(\eta)+\kappa_{2}(\eta)-2 \sqrt{\kappa_{1}(\eta) \kappa_{2}(\eta)}}{4\left(\kappa_{1}(\eta)-\kappa_{2}(\eta)\right)}$, and we show

$F^{\prime}(\eta)=\frac{\left[\kappa_{1}(\eta)+\kappa_{2}(\eta)-2 \sqrt{\kappa_{1}(\eta) \kappa_{2}(\eta)}\right]\left[\kappa_{1}(\eta) \kappa_{2}^{\prime}(\eta)-\kappa_{1}^{\prime}(\eta) \kappa_{2}(\eta)\right]}{4 \sqrt{\kappa_{1}(\eta) \kappa_{2}(\eta)}\left[\kappa_{1}(\eta)-\kappa_{2}(\eta)\right]^{2}}>0 \Leftrightarrow \frac{\kappa_{1}(\eta)}{\kappa_{2}(\eta)}>\frac{\kappa_{1}^{\prime}(\eta)}{\kappa_{2}^{\prime}(\eta)}$

As we know from the proof of Proposition 1, the last inequality is satisfied if and only if $m^{s}<\widehat{m}^{s}$. We conclude that stronger combined network effects $\eta$ mitigate the negative effect of revenue sharing on competitive balance if and only if $m^{s}<\widehat{m}^{s}$. Note that numerical simulations have shown that parts (i) and (ii) of the proposition hold for all parameters $a \in(0,1]$. 


\section{References}

Armstrong, M. (2006), Competition in two-sided markets. RAND Journal of Economics 37: 668-691.

Armstrong, M., J. Wright (2007), Two-sided markets, competitive bottlenecks and exclusive contracts. Economic Theory 32: 353-380.

Atkinson, S., L. Stanley, J. Tschirhart (1988), Revenue sharing as an incentive in an agency problem: An example from the national football league. RAND Journal of Economics 19: 27-43.

Bae, S., J. Kwon (2008), Two-sided network effects and competitive balance in professional team sports. SSRN Working Paper (http://ssrn.com/abstract=1094821).

Baye, M., J. Morgan (2001), Information gatekeepers on the internet and the competitiveness of homogeneous product markets. American Economic Review 91: 454-474.

Becker, G., K. Murphy (1993), A simple theory of advertising as a good or bad. Quarterly Journal of Economics 108: 941964.

Belleamme, P., E. Toulemonde. (2009), Negative intra-group externalities in twosided markets. International Economic Review 50: 245-272.

Borland, J., R. MacDonald (2003), The demand for sports. Oxford Review of Economic Policy 19: 478-502.

Budzinski, O., J. Satzer (2010), Sports business and multisided markets: Towards a new analytical framework. IME Discussion Paper 85.

Buraimo, B., D. Forrest, R. Simmons (2007), Freedom of entry, market size, and competitive outcome: Evidence from English soccer. Southern Economic Journal 74: 204-213.

Caillaud, B., B. Jullien (2003), Chicken \& Egg: Competition among Intermediation Service Providers. RAND Journal of Economics 34: 309-328.

Clark, D., C. Riis (1998), Contest success functions: An extension. Economic Theory 11: 201204.

Crampes, C., C. Haritchabalet, B. Jullien (2009), Advertising, competition and entry in media industries. Journal of Industrial Economics 57: 7-31.

Deloitte \& Touche (2010), Annual review of football finance. Deloitte, Research Report.

Depken, C., D. Wilson (2004), Is advertising a good or a bad? Evidence from U.S. magazine subscriptions. Journal of Business 77: 61-80.

Dietl, H., E. Franck, M. Lang (2008), Overinvestment in team sports leagues: A contest theory model. Scottish Journal of Political Economy 55: 353-368.

Dietl, H., M. Lang (2008), The effect of gate revenue-sharing on social welfare. Contemporary Economic Policy 26: 448-459.

Dietl, H., M. Lang, A. Rathke (2011), The combined effect of salary restrictions and revenue sharing in sports leagues. Economic Inquiry 49: 447-463.

Dietl, H., M. Lang, S. Werner (2009), Social welfare in sports leagues with profitmaximizing and/or win-maximizing clubs. Southern Economic Journal 76: 375-396.

Dixit, A. (1987), Strategic behavior in contests. American Economic Review 77: 891-898.

Downward, P., A. Dawson (2000), The Economics of Professional Team Sports. Routledge, London.

El-Hodiri, M., J.Quirk (1971), An economic model of a professional sports league. Journal of Political Economy 79: 1302-1319.

Evans, D. (2003), The antitrust economics of two-sided markets. Yale Journal of Regulation 20: 325-381.

Evans, D., A. Hagiu, R. Schmalensee (2004), A survey of the economic role of software platforms in computer-based industries. CESifo Economic Studies 51: 189-224.

Evans, D., R. Schmalensee (2007), The industrial organization of markets with twosided platforms. CPI Journal 3.

Farrelly, F., P. G. Quester (2003), The effects of market orientation on trust and commitment. European Journal of Marketing 37: 530-553.

Flynn, M., R. Gilbert (2001), The analysis of professional sports leagues as joint ventures. Economic Journal 111: F27-F46. 
Fort, R., Y. Lee (2007), Structural change, competitive balance, and the rest of the major leagues. Economic Inquiry 45: 519-532.

Fort, R., J. Quirk (1995), Cross-subsidization, incentives, and outcomes in professional team sports leagues. Journal of Economic Literature 33: 1265-1299.

Fort, R., J. Quirk (2011), Optimal competitive balance in a season ticket league. Economic Inquiry 49: 464-473.

Fort, R., J. Winfree (2009), Sports really are different: The contest success function, marginal product, and marginal revenue in pro sports leagues. Review of Industrial Organization 34: 69-80.

Green, J., N. Stokey (1983), A comparison of tournaments and contests. Journal of Political Economy 91: 349-364.

Grohs, R., U. Wagner, S. Vsetecka (2004), Assessing the Effectiveness of Sport Sponsorships - An Empirical Examination. Schmalenbach Business Review (sbr) 56: 119-138.

Grossmann, M., H. M. Dietl, M. Lang (2010), Revenue sharing and competitive balance in a dynamic contest model. Review of Industrial Organization 36: 17-36.

Hirshleifer, J. (1989), Conict and rent-seeking success functions: Ratio vs. difference models of relative success. Public Choice 63: 101-112.

Kaiser, U., J. Wright (2006), Price structure in two-sided markets: Evidence from the magazine industry. International Journal of Industrial Organization 24: 1-28.

Késenne, S. (2000a), The impact of salary caps in professional team sports. Scottish Journal of Political Economy 47: 422-430.

Késenne, S. (2000b), Revenue sharing and competitive balance in professional team sports. Journal of Sports Economics 1: 56-65.

Késenne, S. (2007), The Economic Theory of Professional Team Sports - An Analytical Treatment. Edward Elgar, Cheltenham, UK.

Kotowitz, Y., F. Mathewson (1979), Advertising, consumer information, and product quality. Bell Journal of Economics 10: 566-588.

Lang, M., M. Grossmann, P. Theiler (2011), The sugar daddy's game: How wealthy investors change competition in professional team sports. Journal of Institutional and Theoretical Economics 167: 557-577.

Lazear, E., S. Rosen (1981), Rank-order tournaments as optimum labor contracts. Journal of Political Economy 89: 841-864.

Marburger, D. R. (1997), Gate revenue sharing and luxury taxes in professional sports. Contemporary Economic Policy 15: 114-123.

Nalebuff, B., J. Stiglitz (1983), Prizes and incentives: towards a general theory of compensation and competition. Bell Journal of Economics 14: 21-43.

Nelson, P. (1974), Advertising as information. Journal of Political Economy 82: 729.

Reisinger, M., L. Ressner, R. Schmidtke (2009), Two-sided markets with pecuniary and participation externalities. Journal of Industrial Economics 57: 32-57.

Rochet, J., J. Tirole (2002), Cooperation among competitors: Some economics of payment card associations. RAND Journal of Economics 33: 549-570.

Rochet, J., J. Tirole (2003 a), An economic analysis of the determination of interchange fees in payment card systems. Review of Network Economics 2.

Rochet, J., J. Tirole (2003b), Platform competition in two-sided markets. Journal of the European Economic Association 1: 990-1029.

Rochet, J., J. Tirole (2006), Two-sided markets: a progress report. The RAND Journal of Economics 37: 645-667.

Rottenberg, S. (1956), The baseball players' labor market. Journal of Political Economy 64: 242-258.

Runkel, M. (2006), Total effort, competitive balance and the optimal contest success function. European Journal of Political Economy 22: 1009-1013.

Schmalensee, R. (2002), Payment systems and interchange fees. Journal of Industrial Economics 50(2): 103-122.

Skaperdas, S. (1996), Contest success functions. Economic Theory 7: 283-290. 
Szymanski, S. (2003), The economic design of sporting contests. Journal of Economic Literature 41: 1137-1187.

Szymanski, S. (2004), Professional team sports are only a game: The walrasian fixed supply conjecture model, contest-nash equilibrium and the invariance principle. Journal of Sports Economics 5: 111-126.

Szymanski, S., Késenne, S. (2004), Competitive balance and gate revenue sharing in team sports. Journal of Industrial Economics 52: 165-177.

Tullock, G. (1980), Efficient rent-seeking. Pp. 97-112 in: J. Buchanan, R. Tollison, G. Tullock (eds.), Toward a Theory of Rent Seeking Society. University Press, Texas.

Vrooman, J. (1995), A general theory of professional sports leagues. Southern Economic Journal 61: 971-990.

Vrooman, J. (1996), Baseball players' labor market reconsidered. Southern Economic Journal 63: 339-360.

Vrooman, J. (2008), Theory of the perfect game: Competitive balance in monopoly sports leagues. Review of Industrial Organization 31: 1-30.

Wright, J. (2003), Optimal card payment systems. European Economic Review 47: 587-612.

Wright, J. (2004a), The determinants of optimal interchange fees in payment systems. Journal of Industrial Economics 52: 1-26.

Wright, J. (2004b), One-sided logic in two-sided markets. Review of Network Economics 3.

Prof. Dr. Helmut Dietl, Department of Business Administration, University of Zurich, Plattenstrasse 14, 8032 Zurich, Switzerland.

helmut.dietl@business.uzh.ch

Tobias Duschl, Department of Business Administration, University of Zurich, Plattenstrasse 14, 8032 Zurich, Switzerland.

tobias.duschl@business.uzh.ch

Prof. Dr. Egon Franck, Department of Business Administration, University of Zurich, Plattenstrasse 14, 8032 Zurich, Switzerland.

egon.franck@business.uzh.ch

Dr. Markus Lang, Department of Business Administration, University of Zurich, Plattenstrasse 14, 8032 Zurich, Switzerland.

markus.lang@business.uzh.ch 